EXTENDED REPORT

\title{
Mitomycin $C$ for pterygium: long term evaluation
}

\author{
F Raiskup, A Solomon, D Landau, M Ilsar, J Frucht-Pery
}

Br J Ophthalmol 2004;88:1425-1428. doi: 10.1136/bjo.2003.039891

See end of article for authors' affiliations .....................

Correspondence to: Professor Dr J Frucht-Pery, Department of Ophthalmology, Hadassah University Hospital, POB 12000, 91120 Jerusalem, Israel; fruchtpery@md.huji. ac.il

Accepted 5 April 2004

\begin{abstract}
Aim: To evaluate long term complications after pterygium excision with mitomycin $C(M M C)$ application. Design: Prospective non-comparative interventional case series.

Participants: Ninety nine patients who underwent pterygium surgery and participated in a controlled study for efficacy of MMC for pterygium surgery between 1989 and 1994.

Methods: Patients who were located and agreed to come for examination underwent a complete eye examination. The bare sclera area, in particular, was examined for possible complications. The main outcome measures were anatomical findings in area of $M M C$ application.

Results: Forty three eyes of 43 patients were examined. Sixty three per cent of patients had pterygium surgery with intraoperative application of $0.02 \%$ MMC for 5 minutes and $37 \%$ of patients received MMC $1 \%$ or $2 \%$ drops four times daily for 2 weeks postoperatively. In three patients, pterygium recurred within 18 months. The only complication was mild conjunctival avascularity in areas of pterygium excision in $30 \%$ of patients.

Conclusion: Long term evaluation revealed that the use of $M M C$ in pterygium surgery is safe, but for a strict selection of patients, controlled use of $M M C$ and long term follow up are required.
\end{abstract}

P terygium is a common ocular surface disorder treated by surgical excision. Pterygia are more prevalent in patients living in regions closer to the equator. ${ }^{1}$ Histologically, an epithelial lining covers atrophic conjunctiva that extends beyond the limbus onto the cornea. Underneath this epithelium is a bulky mass of thickened, hypertrophic, and degenerated connective tissue characterised by elastoid degeneration.

One of the major limitations of pterygium excision is the high rate of postoperative pterygium recurrence. The reported postoperative recurrence rate of pterygium excision alone ranges from $55.9 \%^{2}$ to $89 \% .^{3}$ In an effort to reduce the recurrence rate, adjunctive therapy such as beta irradiation, mitomycin C, 5-fluorouracil, and thiotepa have been used with varying success during the last three decades. ${ }^{3-12}$ Mitomycin C (MMC) use, intraoperatively or postoperatively, is one of the adjunctive treatments that can significantly reduce the rate of pterygium recurrence. ${ }^{3-11} \mathrm{MMC}$ is an antibiotic isolated from Streptomyces caespitosus. It is an alkylating agent that is bioreductive because it undergoes metabolic activation through a cytochrome P-450 reductase mediated reaction to create an alkylating agent. MMC damages cells by crosslinking DNA, forming covalent bonds with the guanine in DNA. MMC inhibits the synthesis of DNA, RNA, and protein and is radiomimetic in many of its actions. ${ }^{13-15}$ Uncontrolled use or overdose of MMC may cause severe complications. In the ophthalmic literature, a variety of mild and severe complications were reported when pterygium excision was combined with topical MMC use. ${ }^{35616}$ These complications occurred within the early postoperative period. Only two reports indicated long term complications related to MMC, after pterygium excision. ${ }^{17} 18$

In our institution we have been routinely performing combined pterygium surgery with adjunctive MMC use for more than a decade. Our short term data were previously reported..$^{719}$ In the present paper we report the long term safety of adjunctive use of MMC for pterygium surgery.

\section{PATIENTS AND METHODS}

A prospective study on late complications post pterygium surgery and MMC use was conducted at the Department of
Ophthalmology of Hadassah University Hospital in Jerusalem.

We invited all the patients who underwent pterygium surgery and participated in controlled studies for efficacy of MMC for pterygium surgery between 1989 and 1994. We called each patient according to our records. We included in this study those patients who could be found and who agreed to come for eye examination in the Department of Ophthalmology in Hadassah University Hospital, Jerusalem, Israel.

Altogether 99 patients were treated with MMC between 1989 and 1994. Fifty patients were treated with postoperative $0.1 \mathrm{mg} / \mathrm{ml}$ or $0.2 \mathrm{mg} / \mathrm{ml}$ MMC twice daily for 5 days ${ }^{9}$ and 49 patients were treated intraoperatively with application of $0.2 \mathrm{mg} / \mathrm{ml} \mathrm{MMC} \mathrm{for} 5$ minutes. ${ }^{19}$ The surgical procedure included bare sclera technique leaving 2-3 $\mathrm{mm}$ of bare sclera as described before. ${ }^{19}$ Patients who were located and came for examination underwent a complete eye examination (JFP and FR) including visual acuity, intraocular pressure, ocular surface, and intraocular examination with the help of a slit lamp, and fundoscopy. In particular, the bare sclera area was examined for possible complications such as: thinning and/or ulceration of the sclera allowing visualisation of uveal tissue; calcified lesions; large "bleached" areas of avascular zones, and recurrence of pterygium. Recurrence of pterygium was diagnosed upon the finding of fibrotic vascularised tissue crossing through the limbus.

\section{STATISTICAL ANALYSIS}

Kaplan-Meyer survival analysis was performed to evaluate the cumulative incidence of recurrence, by stratifying primary and recurrent pterygia. The log rank test was used to compare the incidence of recurrence free cases between primary and recurrent pterygia. GraphPad Prism version 2.01 (GraphPad Software Inc, San Diego, CA, USA) was used for data analysis.

Abbreviations: $M M C$, mitomycin $C$. 


\section{RESULTS}

Of 99 patients who underwent pterygium surgery with MMC application, only 43 were available for examination; 50 patients had relocated and six patients did not come for scheduled examination. Forty three eyes of 43 patients (27 males and 16 females) were followed for a mean of 125 months (range 84-156 months). The mean age of examined patients was 51.77 years (range 27-72 years). Twenty seven $(63 \%)$ patients had undergone pterygium surgery with intraoperative MMC application and 16 (37\%) patients had received postoperatively drops of MMC.

The spectacles corrected visual acuity was $20 / 20$ in 31 $(72 \%)$ patients, $20 / 30$ in nine $(21 \%)$ patients and $20 / 40$ in three $(6.9 \%)$ patients. Visual acuity of $20 / 40$ was due to cataract formation in these three patients. Similar cataracts were discovered in the fellow eyes. The intraocular pressure in the studied eyes was between $10 \mathrm{~mm} \mathrm{Hg}$ and $19 \mathrm{~mm} \mathrm{Hg}$ and the pressures in the fellow eyes were within $2 \mathrm{~mm} \mathrm{Hg}$ of the treated eyes. None of the patients used topical medication except for artificial tears.

No serious long term complications were recorded in any of these patients. All patients (except one who had a significant recurrence of pterygium) were asymptomatic (fig $1 \mathrm{~A}$ and B). The only complications we observed were "bleached" conjunctival avascular zones in areas of pterygium excision in 13 (30.2\%; fig $2 \mathrm{~A}$ and $\mathrm{B}$ ) patients and three patients $(6.9 \%)$ who had recurrence of the pterygium. Three $(6.9 \%)$ of these 13 patients had been treated with MMC intraoperatively and $10(23.2 \%)$ had received postoperative MMC. In all patients the avascularity zones were observed within the first postoperative months. In all these patients the overlying conjunctiva looked clinically normal except for a lesser vascular density over the bleached areas. Ten of these patients were asymptomatic. Three $(6.9 \%)$ patients had pterygium recurrence within the first year after the surgery. Two of these three patients presented vascularised fibrotic tissue just crossing the limbus. One patient had recurrent pterygium of $3.5 \mathrm{~mm}$ in diameter. All three were reported as recurrent pterygia in our previous studies. ${ }^{79}$ The mean cumulative proportion of recurrence free patients at 125 months was 0.95 (SD 0.034) for the entire study group (fig 3A), 0.968 (SD 0.032) for patients with primary pterygia, and 0.909 (SD 0.087) for patients with recurrent pterygia (fig 3B). The recurrence rate of primary pterygia was not significantly different compared with that of recurrent pterygia $(\mathrm{p}=0.75$, log rank test).

\section{DISCUSSION}

Singh et al introduced the use of MMC, as an adjunct to pterygium surgery, to Western ophthalmology in $1988 .^{4}$ Although MMC significantly reduced the rate of pterygium recurrence to a range of less than $10 \%$, severe complications such as corneal oedema, corneal perforation, scleral calcification, corectopia, iritis, sudden onset mature cataract, severe secondary glaucoma, incapacitating photophobia, and pain were reported by Singh and others. ${ }^{416}$ These complications occurred within the first postoperative period and were mostly related to uncontrolled use of high cumulative doses of MMC at home or poor selection of patients who had dry eyes or immune disorders. ${ }^{4}{ }^{916}$ Most of these complications can be avoided by using strict inclusion and exclusion criteria, ${ }^{9}$ using MMC intraoperatively only (application of MMC topically for up to 5 minutes) and close control of the patients until the epithelisation of the ocular surface is complete. Using these rules, in the past 13 years we had no MMC related severe complications following pterygium surgery, ${ }^{7}{ }^{19}$ except for some temporary postoperative superficial punctuate keratopathy.
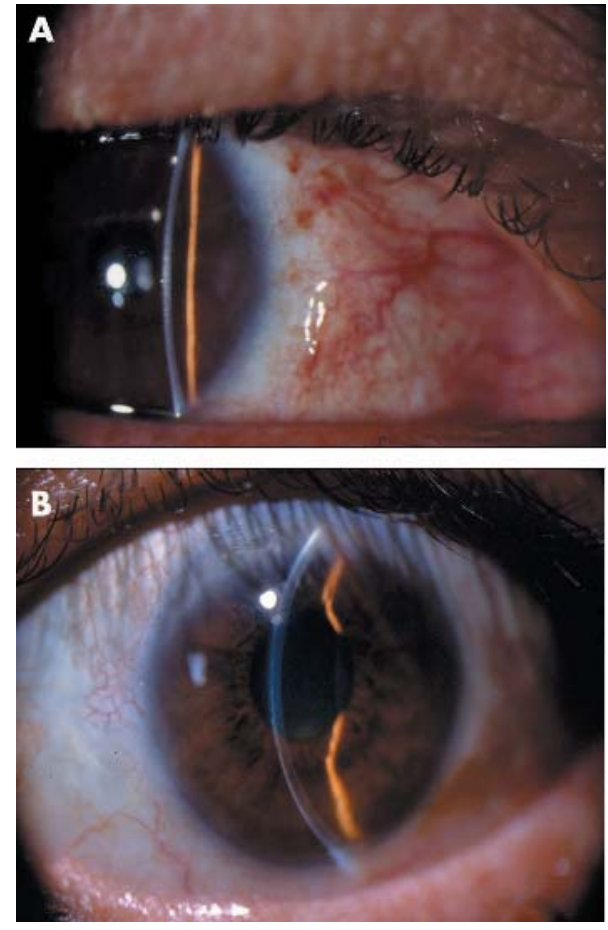

Figure 1 Normal appearance of conjunctiva in a 67 year old male, 9 years after the operation (A) and a 55 year old female, 8 years after the operation (B).
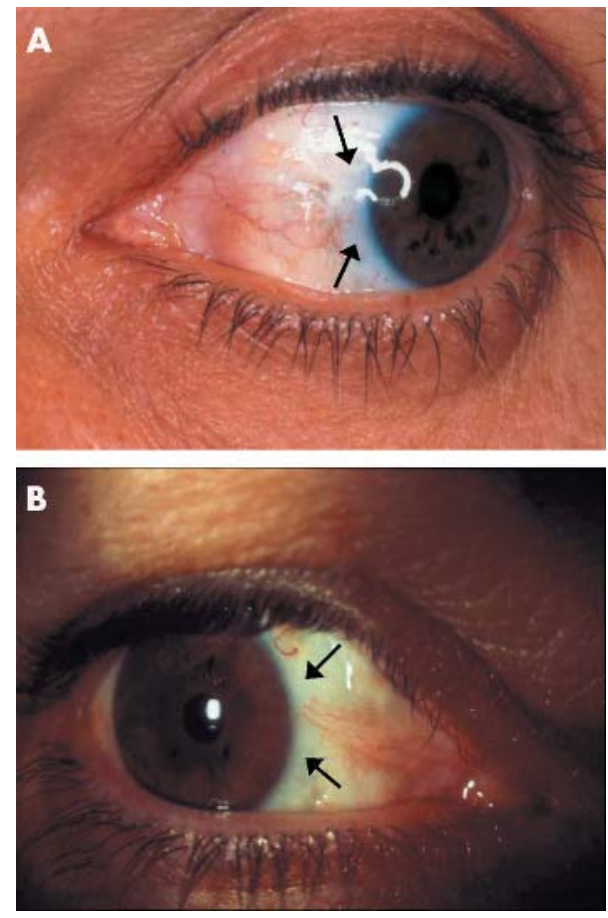

Figure 2 Avascular zones in the area of MMC application (arrows).

Despite the fact that early complications of MMC can be avoided or reasonably controlled, one cannot implicate the outcome of MMC application years after its use. This is a major concern for those who consider routine use of MMC for pterygium surgery and is one of the reasons for the limited use of MMC in ophthalmology. Previous experience with beta irradiation application after pterygium surgery 

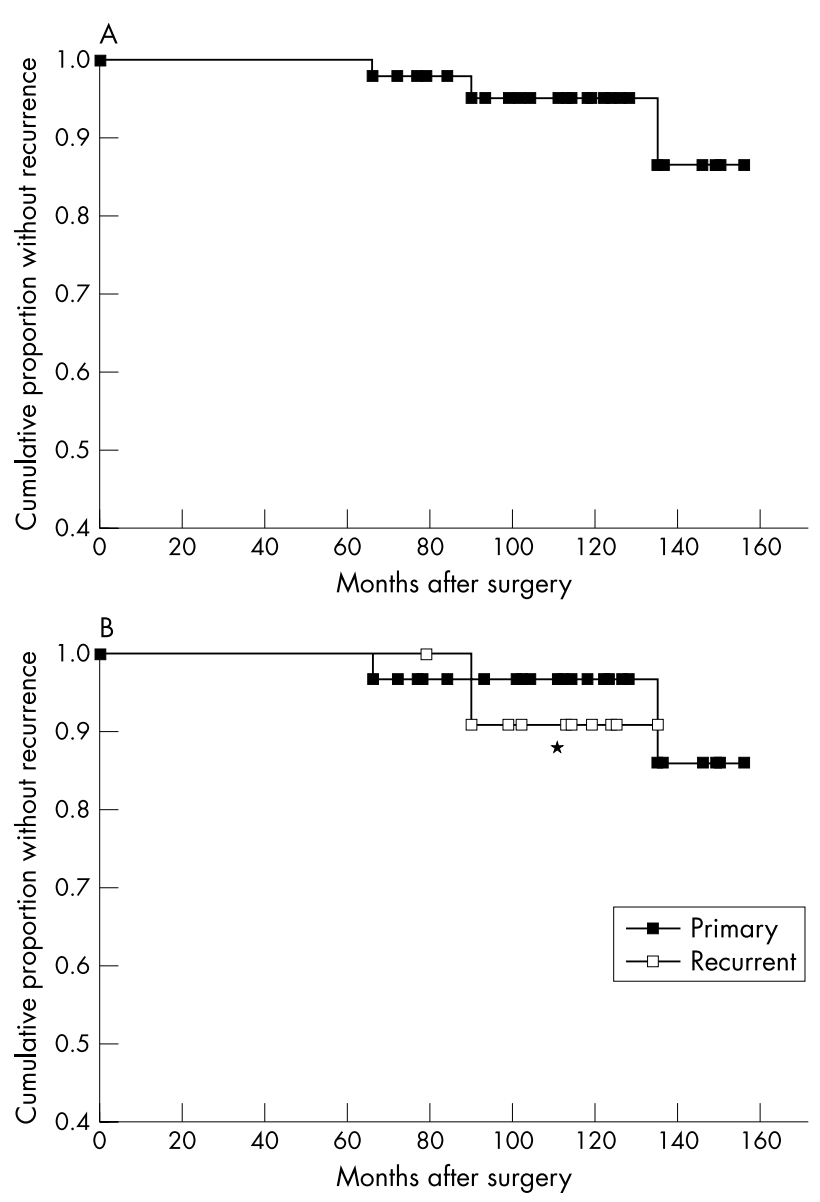

Figure 3 Kaplan-Meyer survival curves of the entire study group (A), and primary and recurrent pterygia (B). The mean cumulative incidence of recurrence free eyes at 125 months was 0.95 (SD 0.034) for all patients, 0.968 (SD 0.032) for primary, and 0.909 (SD 0.087) for recurrent pterygia ( ${ }^{*} p=0.75$, log rank test).

justifies the need for extreme caution. Beta irradiation was a well accepted adjunctive treatment two to three decades ago. ${ }^{20}$ The early post-pterygium results of beta irradiation application indicated efficacy and safety with a low rate of complications. However, long term results revealed a high rate of scleral melt and ulceration, ${ }^{20}$ which were related to the "alkylating agent" like effect of beta irradiation.

These findings discouraged the use of beta irradiation by ophthalmologists. There is very little information available regarding the long term outcome of MMC application in pterygium surgery. Anduze reported 870 cases of primary and recurrent pterygia done between the years 1988 and 1998 by the merest sclera conjunctival flap technique with a single application of $0.1 \mathrm{cc}$ of $0.4 \mathrm{mg} / \mathrm{ml}$ of $\mathrm{MMC}$ to the subconjunctival space. The overall recurrence rate was $0.35 \%$. A total of 60 patients of this cohort were followed for a period of 10 years. The mean follow up time was 5 years. No corneal, scleral, or retinal complications were found..$^{121}$

Fujitani and celleagues ${ }^{18}$ reported a case of corneoscleral ulceration and corneal perforation 33 months after postoperative application of $0.04 \%$ MMC three times a day for 10 days. Another report from Japan describes four patients who underwent pterygium excision and postoperative application of $0.04 \%$ MMC four times daily for $2-3$ weeks. The patients had ocular pain and irritation 18-25 years after treatment. Scleral ulceration with calcified plaque was found; removal of calcified plaques revealed uveal tissue. Scleral patching was successfully performed in these cases. ${ }^{17}$
We report prospective long term results of previously well controlled and studied patients ${ }^{7}{ }^{19}$ who used MMC intraoperatively or after pterygium surgery. All patients underwent similar surgical technique with bare sclera and received various doses of postoperative MMC $(0.1 \mathrm{mg} / \mathrm{ml}$ or $0.2 \mathrm{mg} / \mathrm{ml}$ drops for a week) or a single intraoperative MMC dose of $0.2 \mathrm{mg} / \mathrm{ml}$ for 5 minutes. None of these patients reported ophthalmic signs or symptoms during the 8-11 years following pterygium excision, except in the cases of pterygium recurrence. We found all the eyes to be without loss of vision and having normal intraocular pressure. There was no evidence of ocular degenerative changes, scleritis, or surface ulcerations during the period of 8-11 years after MMC use. The only evidence of MMC use was discovered in $11(25.5 \%)$ patients who presented limited zones (of 2-3 $\mathrm{mm}$ ) of relative avascularity adjacent to the limbus with otherwise normal appearance of conjunctival epithelium. These findings were already discovered in the first months postoperatively. Although we did not measure the avascular zones in the early postoperative period we believe that at the present time these areas are of a smaller size than in the past. The avascular zones were previously reported as a result of MMC induced inhibition of fibrovascular activity. However, it is important that in our patients these zones did not become a site of potential complications such as degenerative calcifications, infections, epithelial breakage, or scleritis. Furthermore, no new recurrences were observed and all the pterygium recurrences in our group were reported in the published studies as occurring during the first postoperative 18 months. ${ }^{79}$ This is of importance because after MMC use the recurrence of pterygium may occur at a late postoperative period. Although almost 100\% of pterygium recurrences occur during the first six postoperative months (when MMC is not applied), in MMC patients one can first identify recurrence within the second year after pterygium excision. $^{919}$ At the present time we apply MMC 0.02\% intraoperatively for 3 minutes and avoid bare sclera by suturing the conjunctiva to the limbus. Our long term experience with MMC application consistently shows no severe complications, and less than $10 \%$ recurrence rate of primary pterygium in a population with $50 \%$ of pterygium recurrence, when adjunctive treatment is not used. ${ }^{79}{ }^{19}$ Our long term experience without complications shows the advantages of our technique, which is relatively short and requires only minor manipulations of the conjunctiva. Other surgical procedures for pterygium surgery including conjunctival autograft with or without limbal cell transplantation or amniotic membrane transplantation are efficacious as well in reducing the rate of pterygium recurrence. ${ }^{22-27}$ These techniques are time consuming, require a skilled and experienced surgeon, and significant excision and manipulations of conjunctiva, and may deplete the stem cell reserves of the cornea. In cases of pterygium recurrence there might be a shortage of conjunctiva or stem cells for retreatment.

Despite the fact that we did not observe any significant long term complications after MMC use, we are aware that only 43 patients of 99 patients were available for long term evaluation in our study. An additional six patients who did not show for our examination claimed (by phone) that they were asymptomatic and had no eye problems. Furthermore, in a small country like Israel patients with significant complications are usually referred for examination by the surgeon, or the surgeon is informed of such an event. We therefore might assume that those who were not available for our examination did not have severe complications.

We feel that adjunctive use of MMC for pterygium is a safe procedure, but requires a strict selection of patients, controlled use of MMC, and long term follow up of these patients. At the present time we advise the use of MMC at a 
concentration of $0.02 \%$ intraoperatively for 3 minutes and not to leave bare sclera. Eyes treated with MMC should be carefully observed for many years. In particular, a very long follow up of the avascular conjunctival area is required.

\section{Authors' affiliations}

F Raiskup, A Solomon, D Landau, M Ilsar, J Frucht-Pery, Department of Ophthalmology, Hadassah University Hospital, Jerusalem, Israel

The authors state that they have no propriety, financial, or any other interest in any device, material, or company described or mentioned in the article.

\section{REFERENCES}

1 Allan BD, Short P, Crawford GJ, et al. Pterygium excision with conjunctival autografting: an effective and safe technique. $\mathrm{Br} J$ Ophthalmol 1993;77:698-701.

2 Kammoun B, Kharrat W, Zovari K, et al. Pterygium: surgical treatment. J Fr Ophtalmol 2001;24:823-8.

3 Singh G, Wilson MR, Foster CS. Mitomycin eye drops as treatment for pterygium. Ophthalmology 1988;95:813-20.

4 Singh G, Wilson MR, Foster CS. Long term follow-up study of mitomycin eye drops as adjunctive treatment of pterygia and its comparison with conjunctival autograft transplantation. Cornea 1990;9:331-4.

5 Hayasaka S, Noda S, Yamamoto Y, et al. Postoperative instillation of lowdose mitomycin $\mathrm{C}$ in the treatment of primary pterygium. Am J Ophthalmol 1988;106:715-18.

6 Hayasaka S, Noda S, Yamamoto Y, et al. Postoperative instillation of mitomycin $C$ in the treatment of recurrent pterygium. Ophthalmic Surg 1989;20:580-3.

7 Frucht-Pery J, Ilsar M, Hemo I. Single dosage of mitomycin C for prevention of recurrent pterygium: preliminary report. Cornea 1994;13:411-13.

8 Mastropasqua L, Carpineto $P$, Ciancaglini $M$, et al. Effectiveness of intraoperative mitomycin $\mathrm{C}$ in the treatment of recurrent pterygium. Ophthalmologica 1994;208:247-9.

9 Frucht-Pery J, Ilsar M. The use of low-dose mitomycin C for prevention of recurrent pterygium. Ophthalmology 1994;101:7597-62.

10 Mahar PS, Nwokora GE. Role of mitomycin C in pterygium surgery. Br J Ophthalmol 1993;77:433-5.
11 Rosenthal G, Shoham A, Lifshitz T, et al. The use of mitomycin in pterygium surgery. Ann Ophthalmol 1993;25:427-8.

12 Gilman AG, Rall TW, Nies AS, Taylor P, eds. Goodman and Gilman's The Pharmacological Basis of Therapeutics, 8th ed, New York: Pergamon Press, 1990:1247-8.

13 Bowman WC, Rand MJ, eds. Textbook of Pharmacology, 2nd ed, Oxford: Blackwell, 1980;3:14-15.

14 Rubinfeld RS, Pfister RR, Stein RM, et al. Serious complications of topical mitomycin-C after pterygium surgery. Ophthalmology 1992;99:1647-54.

15 Frucht-Pery J, Siganos CS, Ilsar M. Intraoperative application of topical mitomycin-C for pterygium surgery. Ophthalmology 1996; 103:674-7.

16 MacKenzie FD, Hirst LW, Kynaston B, et al. Recurrence rate and complications after beta irradiation for pterygia. Ophthalmology 1991;98:1776-81.

17 Anduze AL. Pterygium surgery with mitomycin-C: ten-year results. Ophthalmic Surg Lasers 2001;32:341-5.

18 Solomon A, Pires RT, Tseng SC. Amniotic membrane transplantation after extensive removal of primary and recurrent pterygia. Ophthalmology $2001 ; 108: 449-60$.

$19 \mathrm{Ma} \mathrm{DH}$, See LC, Liau SB, et al. Amniotic membrane graft for primary pterygium: comparison with conjunctival autograft and topical mitomycin $\mathrm{C}$ treatment. Br J Ophthalmol 2000;84:973-8.

20 Sharma A, Gupta A, Ram J. Low-dose intraoperative mitomycin-C versus conjunctival autograft in primary pterygium surgery: long term follow-up. Ophthalmic Surg Lasers 2000;31:301-7.

21 Gris O, Guell JL, del Campo Z. Limbal-conjunctival autograft transplantation for the treatment of recurrent pterygium. Ophthalmology 2000;107:270-3.

22 Figueiredo RS, Cohen EJ, Gomes JA, et al. Conjunctival autograft for pterygium surgery: how well does it prevent recurrence? Ophthalmic Surg Lasers 1997:28:99-104.

23 Lewallen S. A randomized trial of conjunctival autografting for pterygium in the tropics. Ophthalmology 1989;96:1612-14.

24 Hayasaka S, Iwasa Y, Nagaki Y, et al. Late complications after pterygium excision with high dose mitomycin $\mathrm{C}$ instillation. $\mathrm{Br} J$ Ophthalmol 2000:84:1081-2.

25 Anduze AL, Burnett JM. Indications for and complications of mitomycin-C in pterygium surgery. Ophthalmic Surg Lasers 1996;27:667-73.

26 Fujitani A, Hayasaka S, Shibuya Y, et al. Corneoscleral ulceration and corneal perforation after pterygium excision and topical mitomycin-C therapy. Ophthalmologica 1993;207:162-4.

27 Hardten DR, Samuelson TW. Ocular toxicity of mitomycin C. Int Ophthalmol Clin 1999:39:79-90. 